\title{
GANDHI'S SYNTHESIS OF LIBERAL AND COMMUNITARIAN VALUES: ITS BASIS AND INSIGHTS
}

\author{
Sanjay Lal ${ }^{*}$
}

\begin{abstract}
It is well known that notions of individual sovereignty, universal rights, and the duty to follow one's own conscience are central to the philosophy of Mahatma Gandhi. The importance Gandhi places on community, tradition, and fulfilling duties particular to one's place in life is no less noticeable in his writings. That such is the case may indicate an uneasy tension among different elements in Gandhian philosophy (especially from the perspective of the Western political philosophical tradition). In what follows I argue that an underlying harmony in Gandhi's philosophy can be noticed among such classic liberal and communitarian values given his overall views on self-realization. I will then show the value Gandhi's understanding has for contemporary philosophical debates between liberals and communitarians.
\end{abstract}

It is well known that notions of individual sovereignty, universal rights, and the duty to follow one's own conscience are central to the philosophy of Mahatma Gandhi. The importance Gandhi places on community, tradition, and fulfilling duties particular to one's place in life is no less noticeable in his writings. That such is the case may indicate an uneasy tension among different elements in Gandhian philosophy (especially from the perspective of Western political/philosophical traditions). In what follows I argue that an underlying harmony in Gandhi's philosophy can be noticed among such classic liberal and communitarian values given his overall views on self-realization. I will then show the value Gandhi's understanding has for contemporary philosophical debates between liberals and communitarians.

*Dr. SANJAY LAL, Lecturer in Philosophy, Clayton State University. Email: sanjaylal@clayton.edu, meno4900@aol.com. 


\section{Gandhi's Advocacy of Liberal and Communitarian Principles}

There is consensus among scholars of Gandhi's philosophy that the Mahatma embraces both communitarian and liberal elements as crucial to his overall thought. Nicholas Gier writes: "Gandhi's passionate belief in the unity of world religions includes the integration of all cultures, accepting each on their own terms. At the same time, however, he would have insisted with equal passion that each and every person must be treated with equality and respect." (Gier, 2008: 128) Gier further states that for Gandhi, "Liberal filial piety would consist in teaching children loyalty and deference, but also self-reliance, freedom of thought, and independence.” (Ibid: 135) In describing Gandhi's views on education, Douglas Allen notes "His education emphasizes empathy, mutual understanding, cooperation, and tolerance, but it does not advocate uncritical absolute tolerance and passive acceptance." (Ibid: 51) On the Mahatma's religious ethics, Joseph Prabhu remarks: "While (Gandhi) certainly values the self-discipline involved in Kantian self-legislation, had he been presented with a Kantian view, Gandhi would almost certainly have criticized its atomistic and insulated character- the sense that self-legislation is to be carried out free of social ties and local belonging." (Ibid: 170-171)

The above comments reflect three varied aspects of Gandhi's philosophy. Consider his support of a caste system and his opposition to allowing the "untouchables" to have separate elections. There is also his insistence that all religious beliefs which conflict with the dictates of reason be rejected, and his indictment of modern civilization for eschewing religion. We should include as well his belief in the presence of Truth that all should accept in a genuine realist sense even though it can only be understood in light of one's own individual situation as among these varied aspects. Such seemingly antithetical beliefs result from the fact that essential to Gandhian thought is both the notion that we have an independent (seemingly atomistic) self, separate from our particular aims and attachments, and that the proper view of ourselves is relational-that is it is through our relations with each other that we realize who we are supposed to be. In the following, I will seek to explicate Gandhi's basis for thinking that both views are correct as well as indispensable for developing a correct political system. By doing so, I will show the relevance and implications Gandhi's understandings have for modern-day debates among liberal and communitarian political theorists. My aim is to show that both perceived communitarian and 
liberal notions are crucial to Gandhian thought and are combined in a way indicative of Gandhi's overall unique political philosophy. Thus, I will try to add greater substance to the "reformed liberal" label Gier gives Gandhi while discussing more of the Mahatma's overall philosophical commitments-in particular, his avowed identification with classic Hindu philosophy. Unlike Gier, I think there is ample room in Hindu philosophical tradition to make sense of Gandhi as a reformed liberal. This follows given the central traditional Hindu emphasis on a Universal Self. A Self, in other words, all should realize that is continuous with all. At the conclusion of this paper, I will explore possible takeaways Gandhi offers for us in our dealings with tensions that stem from differences between liberal and communitarian understandings.

\section{A Consideration of Key Conceptual Matters}

Before I proceed with my specific arguments and elaborations, it is worth addressing problems that may result from different conceptual understandings of central terms and issues put forth. I do not wish to imply that it is either the Western liberal tradition or pre-modern communal understandings that are responsible for the distinctive Gandhian conception of the self crucial to my arguments. Furthermore, I understand that more than one interpretation of Gandhi's views on religious conversion and caste has emerged from the vast corpus of his writings. I am convinced that my arguments however do not require much by way of specific commitments on such matters but rather rely on essential and key components of Gandhi's discussions of them. It is implications of these parts of Gandhi's views that I hold are of great value in dealing with present day conflicts stemming from differences between liberal and communitarian understandings. Whether I succeed will be left to the reader.

\section{Liberal and Communitarian Disputes: A General Overview}

The tensions between liberal and communitarian perspectives on the right society are quite familiar and seemingly incommensurable. Since the early 1980s, debates between so-called Rawlsian neo-Kantian "individualists" and Hegelian inspired "communitarians", like Michael Sandel, have maintained a prominent place in Western political philosophy. These debates have involved methodological and normative questions concerning such issues as how the self comes into being (or 
how our identities are formed). and what the basis is for forming a genuine community. Different philosophical views on these types of issues are manifest in contemporary disagreements (both within and outside of academic philosophy) that relate to the viability of expecting universal adherence to a given code of human rights, and the appropriateness of the state advancing particular notions of the good. Thus, for example, even though it is widely agreed in Western societies that all children have an equal right to an education, arguments over whether parents should be allowed to have their children taught only in the family's native tongue and traditions necessarily involve different understandings on the importance of shared cultural identity and group pluralism. These, in turn, are matters that relate to ontological questions of how a self comes into being and what the necessary limits are to forming genuine community. Different metaphysical assumptions of the self often lie at the heart of such discords. It has been well noted that liberal perspectives, with their talk of equality, freedom, and rights, are predicated on a conception of an individualized, separate, and atomistic self. Communitarian thinkers, in contrast, have emphasized a self that grows in relation to others within a community and forms an identity only as part of a larger group. Shlomo Avineri and Avner de-Shalit write: "Both communitarian and individualist theories begin with the image of the individual. But the former claims that there are social attachments which determine the self, and thus individuals are constituted by the community of which they are a part. In that sense the individualist image of the self is ontologically false...."

Sandel's notion of the individualist "unencumbered self" serves to advocate this argument. Sandel postulates the image of a person with "constitutive ends", those ends which constitute who the person is. We must consider people's aims and values if we want to understand who they are. We cannot analyze their behavior as if they were abstract entities, as if their values existed somewhere in the distance, "outside", so to speak. This is a critique of the image of the person put forward by the individualists, who tend to distinguish between who one is and the values one has. Thus, while individualists think in terms of the priority of the self over its aims, communitarians regard this distinction and this priority as artificial, even impossible. (Avineri and de-Shalit, 1993: 3) Gandhi's overall thinking as it pertains to matters of community, constitutive ends, and the ontological status of self enables him to harmonize the seemingly incommensurable outlooks of communitarians and individualists in a distinctively promising way. Gandhian thought offers insights by which we can proceed to 
resolve tensions, specific to our time and place, which arise from differences between individualist and communitarian ways of seeing who we are.

\section{Gandhian Insights at Work}

We should consider Gandhi's approach to the conflicts which arose in (and still confront) Indian society involving religious pluralism and the presence of caste structure. To a very significant extent, these conflicts can be seen as real world manifestations of differences between individualist and communitarian presuppositions. Take, for example, conflicts that have arisen from the religious missionary zeal in India to bring locals "to the one truth" which is believed to be needed by all. The attitudes of missionaries in such cases is unmistakably parallel to the much criticized individualist mind-set that one set of codes should command the agreement and assent of all people given a supposed universal human nature. Additionally, the stratification by caste which has characterized Indian society has helped make that society clearly embody the communitarian's point that the groups we belong to (which determine our social attachments) are not primarily ones we voluntarily join. Exploring the acceptability of this kind of stratification goes to the core of the communitarian's point of view.

\section{Gandhi's Takes on Religious Conversion and Castes}

In expounding on the distinction in Gandhian thought between "positive" and "negative" religious conversion, Rajmohan Ramanathapillai gives an illustration of Gandhi's ability to successfully harmonize individualist and communitarian elements. (Ramanathapillai, 2010: 40-49) It should be noted that the criticisms Gandhi levels against those religious missionaries he sees to be engaged in negative proselytization are significantly identical to some of the ones communitarians level against liberal understandings. It is no less notable that the criteria Gandhi uses in determining whether missionary work is "positive" include standard liberal values like self-autonomy, truth, equality, and freedom from state interference. As Ramanathapillai chronicles, two of Gandhi's chief objections to how missionaries went about their work were based on the value of cultural identity and the meaninglessness of performing rituals mechanically with no deeper understanding of their significance. While discussing his criticisms of how missionaries interacted with the animist, aboriginal tribes in the Konda Hills 
of India, Gandhi compares the native people's culture to indigenous plants. (Gandh, 1999: 83) Ramanathapillai elaborates: "Like medicinal plants rooted in native soil, people have an organic relationship with culture and its faith, and this organic wholeness nurtures them, protecting them from crisis and healing their wounds. Negative conversion pulls plants from the soil and puts them in the alien soil of the conqueror. Consequently, not only is the wound between converts and their family and culture ripped open, their cultural identity is destroyed for future generations. For Gandhi, this is 'irreligious and immoral'." (Ibid: 45)

Gandhi's point here contains shades of a modern day criticism of the Enlightenment Project (which is typically seen as a natural outgrowth of individualist political philosophy). Joseph Raz summarizes the point of these critics: "The Enlightenment, they say, has thrown out the baby with the bath water. In recognizing that morality overcomes people's partiality to themselves, the Enlightenment has - those critics claim-created a monster: a universalized individual who is stripped of everything that makes people human, and is reduced to a sheer abstraction. The Enlightenment project is the morality of this abstract individual, and like abstract individuals, it is barren of any content." (Raz, 2010: 586)

If we substitute "missionary religion" (the kind Gandhi has in mind) for "Enlightenment" and "religious truth" for "morality" in the above passage, we can see the concerns referred to therein, not only parallel, but are virtually identical to those expressed in Gandhian thought. Assuming that the objectivity of reality means religious claims should have genuine meaning to us, even when they are abstracted from the individual cultures we identify with, seems to leave us with a religion that would be barren of significant content (in most places anyway) while damaging a needed and specific sense of identification.

Gandhi's point here relates to another major criticism he levels against missionary activity that again parallels a qualm expressed by critics of political liberalism. Gandhi is critical of religious conversion bereft of real inner understanding, on the part of converts, of the beliefs and practices that they now profess and have adopted. He states, "Real conversion springs from the heart and at the prompting of God..." (Gandhi, 1961: 75) As Ramanathapillai also notes, "Gandhi argued that when people are not ready for spiritual change, or when they don't have a complete understanding of what they are changing into, a conversion is meaningless." (Ibid: 41) In other words, Gandhi saw that simply being baptized and not undergoing a genuine inner transformation has no true religious 
significance.

Similarly, it has been argued that by focusing solely on codes of non-discrimination and equal rights (external, ritualistic aspects) and not emphasizing the development of civic virtues, liberal societies are ultimately unable to realize a real sensitivity to the issues and needs of diverse people. In other words, simply outlawing overt discriminatory practices and ensuring procedural fairness is upheld is insufficient for creating a society in which all feel valued. Raz states, "the precepts of multiculturalism cannot be derived from traditional liberal rights..." (Ibid: 591) It is Gandhi's emphasis, however, on such cherished liberal values as self-autonomy, conforming to an objective understanding of truth, and the equality of all that enables him to see some religious conversions as positive. Ramanathapillai writes further: "Positive conversion for Gandhi is self-realization, which requires individuals to examine themselves and spiritually mature without external impediments or interventions. Positive conversions are nonviolent conversions in which prospective converts enjoy the religious autonomy to choose a right spiritual path that is suitable to their nature. Gandhi argues that positive conversion, nurtured by true religious free will does not thrive because of contact through duress; or because of (the) colonizer's religion policies; or because people are manipulated and mislead...Gandhi is unyielding on this subject that spiritual discoveries are personal...." (Ibid: 45)

Additionally, Gandhi's emphasis on a realist conception of truth as well as on equality allows him to accept some religious conversions. Gandhi holds that all of our activities should aim toward realizing Truth. This follows from his belief in a Universal Self (which is equivalent to Truth) whose actualization is life's purpose. Also Gandhi believes that we are all duty bound to practice nonviolence, and that only nonviolence can lead us to Truth. Furthermore, for Gandhi Truth can only be fully realized in a way that is both non-coercive and collective ${ }^{14}$. Thus realizing Truth can be seen as both our shared final end and a goal which necessitates individual autonomy. Indeed it seems clear that Gandhi would say all of us are actually striving for Truth in our varied actions regardless of how aware we may be of this goal. He states, "As a matter of fact we are all...seeking to know the Unknown." (Gandhi, 1955, 12) This provides Gandhi a basis by which to agree with liberal/individualist assumption of a universal human nature, as well as accept the communitarian emphasis on constitutive ends and shared values. It is however considerations of humility, not the perceived cultural bias of realist 
conceptions of truth which enable him to maintain sensitivity toward cultural understandings different from his own. Gandhi states: "Seekers after Truth could only see as through a glass, darkly, so far as inward sight was concerned. It would, therefore, be sheer presumption on their part to 'convert' others to their own faith. God had as many ways of approaching Him as there were human beings." (Ibid: 12)

Since, given our limits as embodied individuals, we can only grasp Truth partially, we must be open to the partial truths of others to advance our own understandings (and thus better reach our ultimate end-Self-realization). Thus, it is insight gained from specific religious teachings (taught within a community) that concerns the limitations of physical existence which gives Gandhi a basis for cultural sensitivity and thus the classic liberal value of equality.

Furthermore, because none of us can have a full grasp of Truth, yet none of us is without at least some partial understanding of it, we must avoid feelings of superiority regarding the ways and understandings of others. When we consider historical facts of religions mutually influencing and borrowing from one another, such an attitude seems only natural. All of those we encounter can help us further our own grasp of things. Hence, a basis emerges in Gandhian thought for both emphasizing the cherished liberal value of equality and joining in the liberal repudiation of dogmatism. It is only when such an attitude of identification with and humility toward others (given that we are all after the same thing ultimately and also our own limitations) underlies our feelings of a shared human nature and equality can religious conversion be acceptable for Gandhi. This kind of positive religious conversion is also compatible with standard liberal values by affirming the self's individual sovereignty. After all it is the individual who should be allowed to decide which religious path is best for him given facts particular to his own empirical existence. Ramanathapillai writes: "Positive conversion is nonviolent; it helps people who are ready for conversion to identify and embrace new spiritual paths appropriate to their nature. Positive conversion does not aim at masses of converts; it is more concerned with adding clarity and religious depths to an individual's spiritual well-being. Gandhi called such conversion a form of self-realization; converts come to the point of conversion only through the power of self-knowledge...." (Verma, 1970: 76), (Positive) conversion is a personal and spiritual self-realization, which is antithetical to institutionalized mass conversion.... (Ibid: 40) Thus even though, as we have seen, concerns of cultural identity are paramount to Gandhi (in keeping with the spirit of 
communitarianism) it is ultimately considerations for a sovereign, seemingly atomistic, self that take priority in deciding the acceptability of religious conversion.

This kind of dual basis can also be seen in Gandhi's justification of caste divisions (varnashrama) within society. On the one hand, Gandhi bases his justification on universal duty and common human needs. Additionally, he claims that problems with caste divisions have arisen because of departures from the classic liberal value of equality. On the other hand, he argues in favor of the caste system on the basis of what is best for each individual given his/her unique place in a community. Notably, Gandhi refers to the observance of an ideal caste structure as giving place to "equality in diversity". (Ibid: 47) Consider the following passages (which I have tried to keep as succinct as possible without sacrificing critical meaning): The law (of caste) is the law of one's being, which one has to fulfil...Varna (caste) is intimately, if not indissolubly, connected with birth, and the observance of the law of Varna means following on the part of us all the hereditary and traditional calling of our forefathers in a spirit of duty... The performance of one's hereditary function is done as a matter of duty...Thus, the function of a Brahmana (member of the priestly caste) is to study and teach the science of spiritual truth. He performs the function, as he cannot do otherwise, as it is the law of his being....

Varna (caste) is determined by birth, but can be retained only by observing its obligations. One born of Brahmana (priestly caste) parents will be called a Brahmana, but if his life fails to reveal the attributes of a Brahmana then he cannot be called a Brahmana. On the other hand, one who is born not a Brahmana but reveals in his conduct the attributes of Brahmana will be regarded as a Brahmana.... Varna thus conceived is no man-made institution but the law of life universally governing the human family. Fulfilment of the law would make life livable, would spread peace and content, end all clashes and conflicts, put an end to starvation and pauperization, solve the problem of population and even end disease and suffering... Though the law of Varna is a special discovery of some Hindu seer, it has universal application. Every religion has some distinguishing characteristic, but if it expresses a principle or law, it out to have universal application... The world may ignore it today but it will have to accept it in the time to come. I would define the law briefly thus: The law of Varna means that everyone shall follow as a matter of duty (Dharma) the hereditary calling of his forefathers, insofar as it is not inconsistent with fundamental ethics. 
The four Varnas have been compared to the four members of the body. If they are members of one body, how can one be superior or inferior to another? (Our) body politic, the body of humanity, would go to pieces, if it were to perpetuate the canker of superiority or inferiority. It is this canker that is at the root of the various ills of our time. It should not be difficult for even the meanest understanding to see that these wars and strife could not be ended except by the observance of the law of Varna. For it ordains that everyone shall fulfill the law of one's being by doing in a spirit of service that to which one is born. (Ibid: 40)

It should not go unnoticed that Gandhi bases the value of equality in his argument above on an understanding of the community as an ontologically basic and whole unit (like an individual body). It additionally bears mentioning that in the same booklet in which the above passages are found, Gandhi also states "But this duty of labor cannot be imposed on anybody." (Ibid: 47)This is the case even though (as we will see below) for Gandhi, it seems, unless a person has truly matured enough to realize his/her specific duty of labor (independently from social expectations), it is best for them to follow their ancestral path. Thus, we again see Gandhi's sensitivity to liberal values like freedom from external interferences. Furthermore, if we discount the importance he gives to hereditary in the above passages but interpret his points to mean that all of us are bound by the moral law to do that which we can most uniquely do best for society (however this is determined); then Gandhi's defense of a caste system does not seem so outlandish. Ultimately, he is agreeing with the standard liberal view that the same basic duties are universally binding on us all. It is how we go about performing the duty of service to our community (which no one can escape) that varies given aspects specific to ourselves as individuals.

\section{The Take away for Liberal/ communitarian Debates}

At times the above discussion may leave one with the impression that Gandhi, like many of us, is simply trying to have his philosophical cake and eat it too when it comes to what he thinks is correct on specific issues. In other words, he is unable to give up important values that are exclusively prominent in both liberal and communitarian camps and winds up putting forth ideas that cannot stand as a consistent whole. However, if we more closely look at his rationale, in the context of his overall philosophy, for taking the above seemingly at odds positions much insight can be gained for us as we deal with tensions that arise for us that relate to 
debates between liberals and communitarians. Consider, for instance, Gandhi's reply to a correspondent critical of his "continually harping on conscience." (Gandhi, 1961, 123-ff) The correspondent writes: "I find youngsters and grown-up people talking utter nonsense under the cover of conscience. What is more, youngsters have become imprudent and grown-up people unscrupulous; can you not prevent this mischief? If you cannot, please withdraw the word from use and stop the drivel that is being said in the name of that sacred but much abused word. Pray tell us who has a conscience? Do all have it? Do cats have a conscience, when they hunt to death poor mice." (Ibid: Vol. I :262) We can see here the correspondent put forth, what amounts to, a version of the famous "liberty equals license" criticism that has often been brought up against liberal political philosophy. Ultimately, critics have charged that granting freedom to form and pursue one's own life plans (as Mill famously proscribes) ultimately leads to morally negligible results. (Richards, 2001) The point here is that freedom to do as one pleases (and thus act in a way that is aligned with one's conscience) inevitably implies freedom from appropriate moral restraint. In Gandhi's informative reply he states:

I must confess the (correspondent's) charge is not without substance...Every virtue has been known to be abused by the wicked. But we do not on that account do away with virtue. We can but erect safeguards against abuse. When people cease to think for themselves and have everything regulated for them, it becomes necessary at times to assert the right of individuals to act in defiance of public opinion. When individuals so act, they claim to have acted in obedience to their conscience. I entirely agree with the correspondent that youngsters as a rule must not pretend to have a conscience. It is a quality or state acquired by laborious training. Willfulness is not conscience.... (Gandhi, 1983: 454)

The extent to which Gandhi's reply sheds light on his overall philosophy can be gleaned when we consider his words here in conjunction with some of his other beliefs. As Douglas Allen and Glynn Richards (among others) have discussed at great length, Gandhi believes that religion should be a significant part of a child's education and that children should be educated in the traditional language of their given community. (Gandhi, 1961: 262) Thus, for Gandhi not only is the right of conscience a valuable individual right that cannot be exercised by youngsters, but 
such individuals should be educated in a manner in line with communitarian values. Therefore, we can infer that on Gandhi's scheme (not unlike Mill's) individuals must first reach a real level of maturity before they can be entrusted with the use of certain central liberal rights and freedoms (like the right of conscience). This conclusion is also implied by Gandhi in regards to the freedom of religion. After all, before conversion can be legitimate for Gandhi the convert must first be ready for it by examining himself and spiritually maturing. Furthermore, it is not a stretch of credulity to think that Gandhi would believe that only those who have undergone such self-examination and maturation are worthy of having the freedom to leave the vocation of their ancestors (while still engaging in tasks they are uniquely suited for). Even most fully realizing an attitude of equality toward all (as opposed to mindlessly accepting equality as a platitude) would, for Gandhi, require a very real level of spiritual maturity. The spiritually mature individual is one, Gandhi says, who can identify with all that exists and "love the meanest of creation as oneself." (Richards, 2001) This kind of person would most clearly exude an attitude of equality toward all.

Given this conclusion, it becomes easier to see Gandhi's basis for conjointly advocating central liberal and communitarian values in his overall philosophy. Since the rights, freedoms, and values cherished by liberals must first be earned by the individual (in much the same way as Gandhi held India must earn its own independence), the ideal state for Gandhi cannot be one which has the primary role of indiscriminately preserving core liberal freedoms for all. Instead, the state should first focus on developing citizens who can be worthy of such freedoms. We must become worthy of acquiring liberal rights, freedoms, and values in order to fully gain self-realization. The only way one can become worthy of these rights and freedoms is by first learning the truths emphasized in a way that is specific to traditions of his particular community. All communities, at their core, emphasize some real (yet partial) understandings of Truth. These are the ones any given individual is in the position of grasping the most clearly. It is only after such truths have been adequately absorbed can one go beyond them to more fully pursue self-realization (which requires exercising cherished liberal rights and freedoms). Given these points, we can see that for Gandhi the state must not abandon the furthering of communitarian concepts in favor of rights and freedoms but rather regard doing so as necessary in order for its citizens, and thus by extension the state itself, to truly realize independence (swaraj). It is only once we (as individual members of a society) have this independence can it make sense 
for us to be entrusted with the awesome duties possessing rights entails. Gandhi remarked to the U.N. Committee working to draft the Universal Declaration of Human Rights: "All rights to be deserved and preserved come from duty well done. From this fundamental statement perhaps it is easy enough to define the duties of man and woman and correlate every right to some corresponding duty to be performed. Every other right can be shown to be a usurpation hardly worth fighting for." (Gandhi, 1983: 454) It is clear that for Gandhi our duties can only be learned as members of particular communities. Thus it is incumbent on state institutions to advance and preserve these communities for citizens to genuinely possess rights-Gandhi sees no other way that liberty can be tempered with virtue.

\section{A Consideration of Some Problems}

Before concluding, it is worthwhile to consider some problems which may present by my account of Gandhi's way of harmonizing liberal and communitarian elements in his philosophy. If, as I have argued, for Gandhi liberal values can be legitimately possessed only after they have been earned, the unmistakable implication seems to be that those who have not put forth the requisite effort have no duty to honor liberal values. Thus those in a community where no one has matured to the point of deserving, say, personal autonomy would have no obligation to respect the autonomy of someone who wishes to leave it. The one seeking to leave, after all, cannot be considered legitimately autonomous. Likewise, those born into a community whose members have not developed in a genuine egalitarian sense would seem to not be morally required to think of others as being equal. Thus instead of a problem like how liberty can co-exist with virtue, for Gandhi issues like how cultural sensitivity can be expected to always co-exist with freedoms and treatment, all are entitled to present problems. How, for example, can Gandhi's philosophy criticize certain traditional Islamic cultures in which religious conversion is met with the death penalty?

In dealing with such problems, the best I hope to do here is offer a general strategy by which they can be resolved. We should remember that for Gandhi the practice of nonviolence (broadly understood) applies to all and is the only way we can realize Truth (which he sees as everyone's ultimate aim). When we deny freedoms to others (and thus not uphold core liberal values) we are invariably 
inflicting violence (however indirectly) on them. Thus, for Gandhi we are ultimately harming ourselves. Given these points, it seems that Gandhi would hold that we are duty bound to honor core liberal values in our treatment of others when they are entailed by the practice of nonviolence. In other words, adopting nonviolent practices necessarily involves upholding certain liberal values as a by-product. The duty to honor such values in our relations, however, is different from what we can expect from others (e.g. liberally conceived rights we believe we are entitled to). Gandhi, as I have shown, believes we must first properly mature before we can legitimately receive these. It then seems reasonable to conclude Gandhi draws a distinction between our duty to respect the rights of others (regardless of how worthy they may be of them) and the rights which we can properly demand others recognize in their dealings with us. Such a distinction is clearly in line with the willingness Gandhi says a nonviolent activist (satyagrahi) should have to endure but never inflict suffering. (Gandhi, 2000: 10) Thus, just as Gandhi holds our duty to be nonviolent to others does not mean we have a duty to avoid the violent behavior of others, he would say our duty to respect certain rights of others does not, in itself, mean we are entitled to others respecting those rights when interacting with us.

\section{Conclusion}

We can see that for Gandhi the true shortcoming of the liberal enterprise has been its failure to help instill in citizens a basis by which liberal rights, freedoms, and values can be understood and thus accepted. Such a basis can only come from understanding ethical duties which make sense to us as members of particular communities. Ultimately, for Gandhi, value neutrality cannot extend to the foundations that underlie the rights, freedoms, and values on which a society is created. This follows since the means for grasping these foundations will remain necessarily varied.

\section{References}

Avineri, Shlomo and de-Shalit, Avner. (Eds.). 1993. Communitarianism and Individualism. Oxford University Press.

Gandhi, M.K. 1955. Truth is God. Ahmedabad: Navajivan Publishing House.

1961. In Search of the Supreme. Vol. III (1961) Ahemdadbad: Navajivan Trust. 
1983. An Autobiography: The Story of My Experiments with Truth. Mineola, NY:

Dover Press

1999. The Collected Works of Mahatma Gandhi. Vol. 75 p. 83. New Delhi: Indian Government Publications Division.

2000. Freedom, and Self-Rule. Parel, Anthony (ed.) Lanham, Maryland: Lexington Books.

Gier, Nicolas. F. 2008. "Nonviolence as a Civic Virtue," in The Philosophy of Mahatma Gandhi for the $21^{\text {st }}$ Century. Douglas Allen, ed. Landham, MD: Rowman \& Littlefield. Richards, Glyn. 2001. Gandhi's Philosophy of Education. Oxford: University Press.

Ramanathapillai, Rajmohan. 2010. "Gandhi on Negative and Positive Conversion," in The Acorn: Journal of the Gandhi-King Society. Vol. 14 no. 1

Raz, Joseph. 2010. "Multiculturalism,” presented as public lecture. University of Bremen. 